\title{
A definição de cursos d’água internacionais e o caso Silala
}

\author{
The Definition of International Watercourses \\ and the Silala Case
}

\section{La définition des cours d'eau internationaux et l'affaire Silala}

\begin{abstract}
Amael Notini Moreira Bahia*
SUMÁRIO: I. Introdução. II. A definição dos cursos d'água internacionais. III. A origem do silala: contextualizaçãa histórica e científica. IV. Conclusão. V. Agradecimentos. VI. Bibliografia.
\end{abstract}

* Universidade Federal de Minas Gerais, Brasil, ORCID ID: https: / / orcid.org/0000-00030020-2529, e-mail: amaelnotini@hotmail.com.

Artículo recibido el 21 de febrero de 2020 Aprobado para publicación el 9 de octubre de 2020 
Resumo: O presente trabalho visa compreender quais as eventuais consequências do enquadramento ou não do Silala, recurso hídrico compartilhado pelo Chile e pela Bolívia, na definição jurídica de curso d'água internacional. A principal hipótese proposta é de que a elemento do todo unitário do conceito de cursos d'água internacionais não obsta o enquadramento do Silala nessa categoria jurídica. Ainda assim, o elemento da desembocadura comum torna necessária a análise das características geográficas desse recurso hídrico transfronteiriço para que um parecer mais claro possa ser proferido, visto que se trata de um índice de razoabilidade apenas verificável perante uma situação concreta.

Palavras-chave: direito dos cursos d'água internacionais, Silala, bacia transfronteiriça.

ABSTRACT: This paper aims to understand the possible consequences of the classification or not of Silala, a water resource shared by Chile and Bolivia, in the legal definition of an international watercourse. The main hypothesis proposed is that the unitary whole element of the concept of international watercourses does not preclude Silala from fitting into this legal category. The element of the common terminus, on the other hand, makes necessary a factual analysis of the geographical characteristics of this transboundary water resource so that a clearer opinion can be given, since it is an index of reasonableness only verifiable in the face of a specific situation.

Key words: International Watercourses Law, Silala, Transboundary Basin.

RÉSUMÉ: Le présent travail vise à comprendre les conséquences possibles de l'encadrement ou non de la Silala, ressource en eau partagée par le Chili et la Bolivie, dans la définition juridique d'un cours d'eau international. La principale hypothèse proposée est que l'élément de l'ensemble unitaire du concept de cours d'eau internationaux n'entrave pas l'encadrement de la Silala dans cette catégorie juridique. L'élément d'écoulement commun, en revanche, rend nécessaire l'analyse des caractéristiques phatiques de cette ressource en eau transfrontalière afin de pouvoir se faire une opinion plus claire, car il s'agit d'un indice de raisonnabilité qui ne peut être vérifié que dans une situation concrète.

Mots-clés: droit des cours d'eau internationaux, Silala, bassin transfrontalier. 


\section{INTRODUÇÃO}

Dentre os significativos acontecimentos que ocorreram ao longo do século XX referentes ao desenvolvimento do direito dos cursos d'água internacionais, o ano de 1997 engloba três dos mais relevantes. O primeiro é a adoção da Convenção dos Usos Não-Navegáveis de Cursos d’Água Internacionais (UNWC), sendo esta uma das tentativas mais expressivas de codificação em matéria de recursos hídricos transfronteiriços no direito internacional e um dos marcos normativos que orientam desde então a redação de tratados sobre o tema. ${ }^{1} \mathrm{O}$ segundo é o proferimento da sentença pela Corte Internacional de Justiça (CIJ) no caso Gabcikovo-Nagymaros (Hungria/Eslováquia), que não apenas destacou a adoção da UNWC, mas também, anunciou o caráter costumeiro do princípio do uso equitativo e racional dos cursos d'água internacionais. ${ }^{2} \mathrm{O}$ terceiro e último acontecimento é a revogação por parte do governo boliviano da concessão outorgada à Ferrocarril de Anto-

1 A UNWC possui uma importância singular no âmbito do direito dos cursos d'água internacionais, e seus dispositivos serão amplamente abordados pelo presente trabalho com o fim de compreender as normas existentes no direito costumeiro internacional nessa matéria. É importante ressaltar, no entanto, que o Chile e a Bolívia não ratificaram essa convenção, de forma que as normas codificadas por ela apenas possuem relevância para o caso analisado na qualidade de normas costumeiras internacionais. United Nations, "UN Watercourses Convention”, Estados Unidos da América, disponível em: http: / / www. unwatercoursesconvention.org / the-convention/; United Nations Treaty Collection, "Status of the Convention on the Law of the Non-Navigational Uses of International Watercourses”, Estados Unidos da América, disponível em: https: / / treaties.un.org/pages /ViewDetails.aspx?src=IND\&mtdsg_no=XXVII-12\&chap ter $=27$ \&lang $=e$.

2 Retomando a decisão da Corte Permanente de Justiça Internacional sobre o Rio Oder, a Corte Internacional de Justiça reafirmou o princípio do uso equitativo, inserindo-o no contexto do direito dos usos não navegáveis de cursos d'água internacionais: "[the] community of interest in a navigable river becomes the basis of a common legal right, the essential features of which are the perfect equality of all riparian States in the user of the whole course of the river and the exclusion of any preferential privilege of any one riparian State in relation to the others" (Permanent Court of International Justice, Territorial Jurisdiction of the International Commission of the River Oder, Judgment No. 16, 1929, P.C.I.J., Series A, No. 23, p. 27). Modern development of international law has strengthened this principle for non-navigational uses of international watercourses as well, as evidenced by the adoption of the Convention of 21 May 1997 on the Law of the Non-Navigational Uses of International Watercourses by the United Nations General Assembly”. International Court of Justice, "Case Concerning the Gabcikovo- 
fagasta à Bolívia para a utilização do Silala, que representou o momento de ruptura entre o Chile e a Bolívia quanto a esse recurso hídrico transfronteiriço. O governo chileno postula que, a partir desse ato, o governo boliviano já indicava sua pretensão de declarar o Silala enquanto um recurso doméstico e de demandar ao Chile que pagasse por sua utilização. ${ }^{3}$ A ruptura que surgiu desse embate culminaria eventualmente na categorização do sistema hídrico do Silala enquanto a única bacia em alto risco na América do Sul e uma das mais vulneráveis do planeta. ${ }^{4}$

Após quase 20 anos, em 2016, surge o processo da Disputa relativa ao Status e Uso das Águas do Silala, no qual são colocados em discussão perante à CIJ a natureza e as limitações do conceito de cursos d'água internacionais, além da existência de um ordenamento jurídico aplicável aos recursos hídricos que se enquadram no escopo dessa definição. Em breve síntese, a controvérsia circunda a discussão acerca da origem física do Silala e as consequências que decorrem desse fato disputado, de forma que a Bolívia alega possuir soberania absoluta sobre esse recurso hídrico transfronteiriço, enquanto o Chile afirma que se trata de um recurso incluído no escopo das normas específicas aplicáveis a cursos d'água internacionais. ${ }^{5}$

Diferentemente do caso Gabcikovo-Nagymaros e de outros casos relativos à utilização de rios internacionais para fins distintos da navegação, tais como o Pulp Mills, ${ }^{6}$ o caso Silala não se baseia na violação das normas substanciais e procedimentais de um tratado relativo à gestão de um recurso hídrico, mas se desenvolve em torno da aplicabilidade de um conjunto

Nagymaros Project (Hungary/Slovakia)”, Holanda, International Court of Justice, 1997, disponível em: https: / /www.icj-cij.org/files/case-related/92/092-19970925-JUD-01-00-EN.pdf.

3 Fuentes, Ximena, "Solicitud de inicio de procedimiento de la República de Chile contra el Estado Plurinacional de Bolivia ante la Corte Internacional de Justicia por el aprovechamiento de las aguas del río Silala (6 de junio del 2016)", Revista Tribuna Internacional, Chile, vol. 5, núm. 9, 2016, p. 204.

4 United Nations Environmental Programme, Hydropolitical Vulnerability and Resilience along InternationalWaters, Quênia, UNEP, 2007, pp. 64 e 65.

5 Lima, Lucas, "The Silala Waters Dispute before the ICJ and the Law on the use of International Rivers for Non-Navigational Purposes”, Questions of International Law, Itália, vol. “Zoom-In” 39, 2017, pp. 1-3.

$6 \mathrm{O}$ caso Pulp Mills (Argentina vs. Uruguai) diz respeito à controvérsia relativa à instalação de uma fábrica de celulose no largo do rio Uruguai. O caso foi resolvido sob a égide do Estatuto do Rio Uruguai, que previa as normas procedimentais e substanciais aplicáveis a esse recurso hídrico transfronteiriço especificamente. 
específico de normas internacionais, aquele aplicável aos cursos d'água internacionais. $^{7}$

Isso acontece porque o Silala é um recurso hídrico compartilhado pelo Chile, à jusante, e pela Bolívia, à montante, cujo fluxo hídrico é influenciado por canais artificiais. Assim, as partes disputam, essencialmente, o nível de influência que essas estruturas artificiais exercem sobre o fluxo do sistema. Essa influência afeta diretamente o enquadramento do Silala no âmbito do direito internacional, de forma que o debate sobre a natureza e os elementos geográficos desse recurso são primordiais para a resolução da controvérsia.

Mesmo diante da disputa técnica acerca dos aspectos geográficos do Silala, é incontroverso que suas águas surgem à aproximadamente 4.500 metros acima do nível do mar, são formadas a partir de diversos canais e nascentes derivados de um aquífero que também é compartilhado pelos dois países, e confluem com as águas do Rio Helado para formar o Rio San Pedro de Incaliri, um tributário do Rio Loa. ${ }^{8}$ Apesar do fluxo tímido do Silala (aproximadamente $0.150 \mathrm{~m}^{3} / \mathrm{s}$ na região da fronteira), esse recurso possui uma importância singular, visto que está situado no Deserto do Atacama, onde a disponibilidade de recursos hídricos é extremamente escassa. ${ }^{9}$

Para compreender a situação particular que se apresenta no caso Silala, o trabalho adota um marco teórico-conceitual, que consiste na análise do conteúdo das normas jurídicas nacionais e internacionais em face dos aspectos históricos e geográficos que circundam o caso concreto. Essa construção é realizada a partir dos elementos gerais e limitações do conceito de cursos d'água internacionais na doutrina e jurisprudência internacional, para então observar as peculiaridades do caso Silala, na forma como se passa a expor.

De início, a seção II discute os limites da definição de cursos d'água internacionais, perpassando a análise dos seus elementos constitutivos e do seu processo de formação. Dessa forma, os elementos factuais do caso Silala serão discutidos à luz dos elementos normativos da definição de cursos d'água internacionais na tentativa de moldar algumas considerações preliminares sobre o enquadramento jurídico do recurso compartilhado em questão.

7 Lima, Lucas, op. cit.

8 Mulligan, Brendan e Eckstein, Gabriel, "The Silala/Siloli Watershed: Dispute over the Most Vulnerable Basin in South America”, Water Resources Development, Estados Unidos da América, vol. 27, núm. 3, 2011, pp. 595 e 596.

9 Idem. 
Em segundo lugar, a seção III delineia o contexto no qual se desenvolve a controvérsia do Silala. Apesar da escassez de provas efetivas da situação de fato e da cadência de acontecimentos que culminaram no atual estado da controvérsia, o presente trabalho irá apresentar as versões das partes, considerando principalmente os pontos de convergência na argumentação dos litigantes. Assim, serão apresentados todos os elementos factuais levantados pelas partes, sem prejuízo à eventual reconstituição dos fatos a ser realizada pela CIJ.

Com base nessas perspectivas, o trabalho apresenta as potenciais contribuições que podem ser derivadas dos cenários fáticos apresentados pelas partes, bem como suas consequências para o Silala. Argumenta-se, então, que o direito internacional pode ser significativamente alterado pela sentença proferida no caso Silala.

\section{A DEFINIÇÃO DOS CURSOS D’ÁGUA INTERNACIONAIS}

A definição do termo curso d'água internacional ocupa lugar central da disputa acerca do Silala, visto que delimitará o regime jurídico aplicável a esse recurso. Tal conceito surgiu e foi desenvolvido no âmbito da Comissão de Direito Internacional (CDI), tendo sido moldado, primordialmente, por meio de estudos acerca dos tratados existentes sobre o tema e da opinião majoritária dos Estados. ${ }^{10}$ Entretanto, para que houvesse essa opinião majoritária, foi necessário realizar uma compatibilização entre as duas posições dominantes dos Estados à época acerca da abrangência geográfica do conceito.

Desse modo, observando os Estados que se pronunciaram perante a CDI sobre a abrangência geográfica dos trabalhos desenvolvidos, percebe-se um conflito entre os Estados que defendiam a adoção do conceito de "rio internacional”, mais restritivo, e aqueles que, por outro lado, eram favoráveis ao conceito de "bacia de drenagem", mais abrangente. Criou-se, assim, um conceito que combina elementos das duas definições. ${ }^{11}$

10 Arcari, Maurizio, "The Codification of the Law of International Watercourses: The Draft Articles Adopted by the International Law Commission”, Anuario Español de Derecho Internacional, Espanha, vol. 13, 1997, pp. 3-32.

11 Idem. 
É essencial compreender o contexto de criação desse novo conceito, bem como os conceitos que deram origem a este, para então investigar efetivamente os elementos e a interpretação da definição de cursos d'água internacionais, um conceito que engloba os recursos hídricos transfronteiriços superficiais e seus componentes hídricos anexos que fluem em um sentido comum.

Para tanto, será apresentado inicialmente o contexto de construção desses conceitos. Em seguida, serão analisados os elementos constitutivos da definição de cursos d'água internacionais, o "todo unitário" e a "desembocadura comum”. A compreensão desses elementos será essencial para distinguir os diferentes tipos de recursos hídricos transfronteiriços que englobam, em diversas escalas, canais artificiais, e para formular algumas considerações sobre a possibilidade de enquadramento do Silala nesse conceito, em vista das versões conflitantes dos Estados litigantes.

\section{A Criação do Conceito de Cursos d'água Internacionais}

A harmonização dos conceitos de rio internacional e de bacia de drenagem para criar a definição de curso d'água internacional foi um processo gradual, visto que esses conceitos são fortemente divergentes. O rio internacional, uma das primeiras definições internacionais na matéria de recursos hídricos tranfronteiriços, foi introduzido pelo Ato Final do Congresso de Viena de 1815. Essa definição foi defendida por diversos países, entre estes o Brasil, e seu escopo geográfico se limita a rios que trespassam fronteiras de dois ou mais Estados. ${ }^{12}$

Entretanto, esse termo era utilizado para delimitar o escopo geográfico dos rios transfronteiriços para fins de navegação. O regime jurídico dos recursos hídricos compartilhados para fins outros que a navegação foi concebido apenas um século mais tarde, contando com contribuições essenciais

12 Assim como o Brasil, grande parte dos países da América Latina favoreceram o conceito de rio internacional. Entretanto, o Chile e a Bolívia não se pronunciaram sobre a matéria durante os trabalhos de codificação da CDI. República Federativa do Brasil, "Replies of Governments to the Commission's Questionnaire”, Yearbook of the International Law Commission, Estados Unidos da América, Organização das Nações Unidas, 1976, vol. II, núm. 1. 
do Instituto de Direito Internacional (IDI) ${ }^{13}$ Em sua Conferência de Madri, o IDI proclamou princípios gerais que deveriam reger o gerenciamento dos rios transfronteiriços, instrumento esse que não possuía caráter vinculante, mas visava orientar a prática dos Estados no âmbito dessa matéria. ${ }^{14}$

Posteriormente, esse conceito é adotado na Declaração de Assunção sobre o Uso de Rios Internacionais, em 1971. A declaração realiza uma separação dos rios em contíguos e sucessivos, estabelecendo dois regimes paralelos de utilização. ${ }^{15}$ Nesse sentido, os rios contíguos consistem naqueles que estabelecem o limite fronteiriço entre os Estados, enquanto os rios sucessivos são aqueles que efetivamente atravessam fronteiras estatais. ${ }^{16}$ Conforme a Declaração de Assunção, os rios contíguos estariam sob a tutela de ao menos duas soberanias estatais, de forma que seria necessário um acordo prévio a qualquer utilização das águas do recurso. ${ }^{17}$ Em contrapartida, os rios sucessivos estariam regidos por soberanias alternativas, sendo o Estado à montante detentor da parte superior do rio e o Estado à jusante possessor da parte inferior, existindo apenas o dever de não causar danos significativos aos outros Estados riparianos. ${ }^{18}$

Apesar de lograr de uma aceitação considerável por uma parte dos Estados à época do início dos trabalhos da CDI, tal definição se limitava a rios transfronteiriços, excluindo de seu escopo até mesmo outros recursos hídricos superficiais transfronteiriços, tais como os lagos. ${ }^{19}$ Considerando essa limitação estrita do escopo geográfico, o próprio IDI já havia alterado a nomenclatura desse tópico de trabalho para curso d'água ou bacia de

13 Institut de Droit International, "Réglementation internationale de l'usage des cours d'eau internationaux en dehors de l'exercice du droit de navigation. Session de Madrid (1911)", Suíça, Institut de Droit International, 1911, disponível em: http: / /www.idi-iil.org/app /uploads/2017/06/1911_mad_01_fr.pdf.

14 Teclaff, Ludwik, "Evolution of the River Basin Concept in National and International Water Law”, Natural Resources Journal, Estados Unidos da América, vol. 36, núm. 2, 1996, p. 366.

15 República Federativa do Brasil, "Declaration of Asunción on the Use of International Rivers”, Itália, disponível em: http: / / www.fao.org/docrep/005/w9549e/w9549e03.htm.

16 Cavalcanti, Themistocles, "Problemas jurídicos dos rios internacionais", Revista de Ciência Política, Brasil, vol. 23, núm. 3, 1980, p. 27.

17 República Federativa do Brasil, "Declaration of Asunción...”, cit.

18 Idem.

19 Caflisch, Lucius, "Règles Générales du Droit des Cours d'Eau Internationaux”, Collected Courses of the Hague Academy of International Law, Brill-Nijhoff, vol. 219, 1989, p. 31. 
Esta revista forma parte del acervo de la Biblioteca Jurídica Virtual del Instituto de Investigaciones Jurídicas de la UNAM

drenagem à época da codificação da CDI, mesmo que não houvesse uma definição clara dos novos termos utilizados. ${ }^{20}$

Nesse sentido, a outra definição apresentada foi a de bacia de drenagem, um conceito que foi desenvolvido em âmbito doutrinário e adotado no art. II das Regras de Helsinque, da Associação de Direito Internacional (ADI). ${ }^{21}$ Tal conceito apresenta uma maior abrangência geográfica, englobando toda a área que contribui para o abastecimento de um conjunto hídrico que flui em um sentido comum. ${ }^{22}$ Essa definição resulta, assim, de um movimento de Estados que defendia a adoção de um conceito mais abrangente, compreendendo um corpo de normas mais desenvolvido e voltado à proteção ambiental.

O conceito de bacia de drenagem representa uma unidade hidrológica indivisível que requer uma consideração global dos seus elementos para possibilitar uma utilização mais equitativa do recurso compartilhado. ${ }^{23} \mathrm{Os}$ Estados que compõem uma bacia hidrográfica não são apenas aqueles que dividem o rio principal que integra o todo unitário, mas também todos aqueles que contribuem para o abastecimento hídrico da bacia. ${ }^{24}$

Esse conceito foi recebido de diversas formas pelos Estados. Houve aqueles que apoiaram a adoção desse conceito sem nenhuma reserva, tais como a Finlândia e os Estados Unidos da América, ${ }^{25}$ como também alguns Estados que consideraram adequado adotar o conceito de bacia de drena-

20 Institut de Droit International, "Utilisation des eaux internationales non maritimes (en dehors de la navigation). Session de Salzbourg (1961)”, Suíça, Institut de Droit International, 1961, disponível em: http://www.idi-iil.org/app/uploads/2017/06/1961_salz_01_fr.pdf.

21 "An international drainage basin is a geographical area extending over two or more States determined by the watershed limits of the system of waters, including surface and underground waters, flowing into a common terminus". International Law Association, “The Helsinki Rules”, Estados Unidos da América, International Law Association, 1966, artigo II, disponível em: https: / / www.internationalwaterlaw.org/documents/intldocs/ILA / Helsinki_Rules-ori ginal_with_comments.pdf.

22 Idem.

23 Idem.

24 Ibidem, artigo III.

25 Republic of Finland, “Replies of Governments to the Commission's Questionnaire”, Yearbook of the International Law Commission, Estados Unidos da América, Organização das Nações Unidas, 1976, vol. II, núm. 1; United States of América, "Replies of Governments to the Commission's Questionnaire”, Yearbook of the International Law Commission, Estados Unidos da América, Organização das Nações Unidas, 1976, vol. II, núm. 1. 
gem apenas para os efeitos ligados à poluição, mas recusaram a aplicação desse conceito para a análise normativa da utilização dos recursos hídricos compartilhados. ${ }^{26}$ Contudo, uma parcela considerável dos Estados posicionou-se contrária a esse conceito, visto que desejavam que a CDI iniciasse seus trabalhos com base em um escopo mais restritivo. ${ }^{27}$ Alguns Estados, tais como a Bulgária e a România, consideravam que as questões jurídicas relativas a cursos d'água internacionais eram demasiadamente diversas e singulares, de forma que seu processo de codificação seria uma empreitada muito difícil, ou até mesmo impossível. ${ }^{28}$

Ainda assim, não obstante essa forte disputa inicial, quase a totalidade dos Estados consultados tomaram a posição de que a definição do escopo seria relevante apenas enquanto um meio para a discussão do tema essencial, que seriam os problemas jurídicos relativos à disputa de dois ou mais Estados por um sistema hídrico internacional. ${ }^{29}$ Como argumentado pela Argentina, a especificação de uma definição seria desnecessária e até mesmo inapropriada, visto que seria possível progredir sem se perder em um debate acadêmico prolongado que muito provavelmente não produziria conclusões efetivas. ${ }^{30}$ Dessa forma, Richard Kearney, o primeiro relator desse tema, decidiu trabalhar o tópico sem se ater à discussão acerca da definição, alegando ser a prática usual da CDI utilizar definições provisórias enquanto analisa as normas substanciais. ${ }^{31}$

Em seguida, o sucessor de Kearney na relatoria do tema de cursos d'água internacionais, Stephen Schwebel, realizou a primeira tentativa de convergência entre os conceitos de bacia de drenagem e rio internacional, apesar das adversidades encontradas no processo. Ao analisar a dicotomia do todo

26 Kearney, Richard, "First Report on the Law of Non-Navigational uses of International Watercourses”, Yearbook of the International Law Commission, Estados Unidos da América, Organização das Nações Unidas, 1976, vol. II, núm. 1, p. 185.

27 Kearney, Richard, op. cit., p. 184.

28 Wescoat, James, "Beyond the River Basin: Changing Geography of International Water Law Problems and International Watercourses Law”, Colorado Journal of International Environmental Law and Policy, Estados Unidos da América, vol. 3, núm. 1, 1992, p. 307.

29 Kearney, Richard, op. cit., p. 185.

30 Republica Argentina, "Replies of Governments to the Commission's Questionnaire”, Yearbook of the International Law Commission, Estados Unidos da América, Organização das Nações Unidas, 1976, vol. II, núm. 1.

31 Kearney, Richard, op. cit., p. 185. 
unitário de uma bacia hidrográfica frente à fragmentação política da unidade natural embutida no conceito de rio internacional.

Schwebel ressaltou a dificuldade de conciliar essas teorias no âmbito teórico. ${ }^{32}$ Além disso, o relator destacou que a maior parte dos Estados favoráveis ao conceito de bacia de drenagem eram Estados predominantemente à jusante dos recursos hídricos transfronteiriços, e que, de forma similar, a maioria dos Estados defensores do conceito de rios internacionais eram Estados à montante de tais recursos. ${ }^{33} \mathrm{~A}$ explicação desse fenômeno acompanha grande parte das discussões relativas aos cursos d'água internacionais, visto que em grande parte os conflitos se resumem à tentativa dos Estados à montante de limitar a aplicabilidade e os efeitos das normas aos recursos hídricos transfronteiriços. Enquanto os Estados à jusante visavam estabelecer um escopo de aplicação abrangente e normas que garantissem uma efetiva proteção dos recursos compartilhados. ${ }^{34}$

Assim, em um contexto de estagnação das discussões sobre o conceito de cursos d'água internacionais, dada a decisão de postergar os debates relativos à definição do escopo geográfico dos trabalhos em curso, surgiu o conceito de "sistema de cursos d'água", descrito por Schwebel como uma moldura refinada do conceito de bacia de drenagem..$^{35} \mathrm{O}$ sistema de cursos d'água consiste em um todo unitário que engloba não apenas os rios superficiais transfronteiriços, mas também outras unidades hidrográficas, tais como lagos e canais. ${ }^{36}$ Essa definição foi criada com o intuito de servir apenas enquanto uma base provisória para os trabalhos da CDI, tentando conciliar a ênfase nos rios superficiais transfronteiriços com a teoria do todo unitário, e foi logo retirada do projeto de artigos pelo relator subsequente, Jens Evensen. ${ }^{37}$

32 Schwebel, Stephen, "First Report on the Law of Non-Navigational uses of International Watercourses", Yearbook of the International Law Commission, Estados Unidos da América, Organização das Nações Unidas, 1979, vol. II, núm. 1.

33 Idem.

34 Idem

35 International Law Commission, "Summary Record of the $1554^{\text {th }}$ Meeting", Yearbook of the International Law Commission, Estados Unidos da América, Organização das Nações Unidas, 1979, vol. 1 .

36 Schwebel, Stephen, "Second Report on the Law of Non-Navigational uses of International Watercourses", Yearbook of the International Law Commission, Estados Unidos da América, Organização das Nações Unidas, 1982, vol. II, núm. 1.

37 Wescoat, James, op. cit., p. 314 e 315. 
Após um período de confusão terminológica e retrocesso na definição dos cursos d'água internacionais, o quarto relator sobre o tema, Stephen McCaffrey, retornou a palavra sistema em colchetes à proposta de definição, e tomou a posição de que seria necessário discutir um conceito apenas quando o projeto de artigos estivesse mais consolidado. ${ }^{38}$ Desse modo, a definição do escopo dos trabalhos desenvolvidos pela CDI foi apenas apresentada de forma mais consistente em 1991. A fórmula, então, adotada seria apenas levemente alterada antes de adquirir sua forma final, codificada pela UNWC. ${ }^{39}$ A definição possui em si dois elementos centrais e mutualmente complementares, sendo eles o "sistema unitário" e a "desembocadura comum”: "Artigo 2o. Termos utilizados. b) «Curso d'água» significa um sistema de águas superficiais e subterrâneas que, em virtude do seu relacionamento físico, constituem um sistema unitário e normalmente fluindo para uma desembocadura comum". ${ }^{40}$

Uma vez evidenciado o histórico bem como os posicionamentos conflitantes que culminaram na adoção da fórmula conceitual dotada em 1991, faz-se necessária a identificação dos elementos presentes neste conceito, que seria posteriormente reconhecido como costumeiro pela jurisprudência e pela doutrina internacional.

\section{Elementos constitutivos do conceito}

de cursos d'água internacionais

Conforme ilustra a definição proposta pelo artigo 2o. da UNWC, o conceito de cursos d'água internacionais apresenta dois elementos constitutivos: o sistema unitário e a desembocadura comum. Tais elementos constitutivos podem ser entendidos a partir de um embate histórico entre as

38 Ibidem, p. 317.

39 Arcari, Maurizio e Tanzi, Attila, The United Nations Convention on the Law of International Watercourses: A Framework for Sharing, Holanda, Kluwer Law International, 2001, p. 58.

40 Todas as citações diretas do presente trabalho foram traduzidas de forma livre no corpo do texto, e suas versões originais podem ser encontradas nas notas de rodapé respectivas. "Article 2. Use of terms. (b) «Watercourse» means a system of surface waters and groundwaters constituting by virtue of their physical relationship a unitary whole and normally flowing into a common terminus". United Nations, "UN Watercourses Convention”, op. cit. 
Esta revista forma parte del acervo de la Biblioteca Jurídica Virtual del Instituto de Investigaciones Jurídicas de la UNAM

tentativas de ampliar e reduzir o âmbito de aplicação das normas codificadas pela CDI. Nesse sentido, o elemento de sistema unitário foi criado de forma a englobar todos os componentes da complexa realidade hidrológica dos recursos hídricos transfronteiriços ${ }^{41}$ a fim de solucionar a principal limitação do conceito de rio internacional. Tal limitação é de ordem geográfica, referindo-se à negligência dos recursos hídricos transfronteiriços outros que os rios superficiais que atravessam fronteiras. Essa negligência impossibilitaria uma regulação unificada de recursos naturais que são conectados e interdependentes. ${ }^{42}$

O elemento da desembocadura comum, em sentido contrário, foi criado com o intuito de limitar o escopo geográfico de aplicação das normas referentes aos cursos d'água internacionais, ${ }^{43}$ uma vez que a bacia de drenagem possui uma abrangência considerada exacerbada por uma parcela significativa dos Estados por englobar em seu escopo as terras que circundam os recursos hídricos transfronteiriços. ${ }^{44} \mathrm{~A}$ partir dessas perspectivas, as peculiaridades desses elementos serão abordadas nas próximas seções.

\section{A. O Sistema Unitário}

O sistema unitário, primeiro elemento do conceito de cursos d'água internacionais, demonstra uma visão holística dos componentes hídricos que compõem um curso d'água. As próprias normas concebidas pela CDI pressupunham a consideração da integridade do sistema hidrológico, visto que os efeitos de uma atividade realizada em uma parte do sistema podem afetar todo o resto dos componentes hídricos anexos. ${ }^{45}$ Dessa forma, o regime

${ }^{41}$ Arcari, Maurizio, "The Draft Articles on the Law of International Watercourses Adopted by the International Law Commission: An Overview and some Remarks on Selected Issues”, Natural Resources Forum, vol. 21, núm. 3, 1997, p. 171.

42 Caflisch, Lucius, op. cit., p. 31.

43 International Law Commission, "Draft Articles on the Law of the Non-Navigational uses of International Watercourses and Commentaries Thereto and Resolution on Transboundary Confined Groundwater", Yearbook of the International Law Commission, Estados Unidos da América, Organização das Nações Unidas, 1994, vol. II, part two, p. 90.

44 Sette-Câmara, José, "Pollution of International Rivers", Collected Courses of the Hague Academy of International Law, Holanda, Leiden, Brill-Nijhoff, vol. 186, 1984, p. 128.

45 McCaffrey, Stephen, "The UN Convention on the Law of the Non-Navigational uses of International Watercourses: Prospects and Pitfalls", Suíça, p. 18, disponível em: https: / / www. unece.org/fileadmin/DAM/env/water/cwc/legal/UNConvention_McCaffrey.pdf. 
do uso equitativo de recursos compartilhados pode ser influenciado por interferências em qualquer parte do sistema, e não apenas na região artificialmente delimitada pelo conceito de rio internacional, ou seja, em rios superficiais contíguos e sucessivos. ${ }^{46} \mathrm{~A}$ mesma assertiva também se aplica à norma da proibição do dano transfronteiriço e às disposições relativas às medidas planejadas. ${ }^{47}$

Ressalva-se, no entanto, que a UNWC foi redigida com um foco primordialmente voltado às águas superficiais. Assim, o componente transfronteiriço central do sistema unitário deve ser um recurso hídrico superficial, de forma que as águas subterrâneas apenas compõem um curso d'água de forma subsidiária, ou seja, se conectadas ao componente transfronteiriço central. ${ }^{48}$ Entretanto, resta o questionamento de quais elementos superficiais podem ser enquadrados no conceito de cursos d'água internacionais independentemente de estarem conectados à um outro corpo d'água transfronteiriço.

Quanto a essa questão, a CDI não estabelece qualquer critério aparente de hierarquia entre as águas superficiais no projeto de artigos da UNWC. Portanto, os elementos superficiais do todo unitário de um curso d'água internacional podem assumir diversas formas, naturais (ex: lagos ou rios) e artificiais (ex. canais), sem subordinação entre si. ${ }^{49}$

Assim, a CDI estabelece basicamente dois critérios para a delimitação do todo unitário de um curso d'água internacional, sendo estes a presença de um recurso hídrico transfronteiriço superficial e a interdependência física dos elementos constitutivos do sistema hídrico em questão. ${ }^{50}$ Dessa forma, restariam excluídos do escopo geográfico da UNWC apenas as águas subterrâneas não conectadas a um corpo d'água superficial transfronteiriço. ${ }^{51}$

46 McCaffrey, Stephen, "Seventh Report on the Law of Non-Navigational uses of International Watercourses", Yearbook of the International Law Commission, Estados Unidos da América, Organização das Nações Unidas, 1991, vol. II, núm. 1, p. 50.

47 Idem.

48 Eckstein, Gabriel e Eckstein, Yoram, “A Hydrogeological Approach to Transboundary Ground Water Resources and International Law”, Am. U. Int'l L. Rev, vol. 19, 2003, p. 241.

49 McCaffrey, Stephen, "Seventh Report...”, cit., p. 51.

50 International Law Commission, "Draft Articles on the Law of the Non-Navigational uses...", cit., p. 90 .

51 Idem. 
Considerando o caso específico dos canais, estes foram expressamente incluídos na lista exemplificativa dos seus elementos constitutivos, sendo assim introduzidos no escopo geográfico de cursos d'água internacionais. ${ }^{52}$ Contudo, tal inclusão foi objeto de controvérsia, sendo que alguns dos membros da Comissão consideraram enquanto um pressuposto que os cursos d'água poderiam ser fruto exclusivo de fenômenos naturais. ${ }^{53}$

Ainda assim, considerando a evolução do conceito de cursos d'água internacionais, ressalta-se que o acordo que possibilitou um maior consenso entre os Estados foi a expansão do escopo geográfico do conceito tradicional de rio internacional para abranger todo o sistema unitário de águas superficiais transfronteiriças, bem como as águas subterrâneas anexas, sem incluir, no entanto, as terras da região da bacia de drenagem..$^{54}$ Não há aqui qualquer limitação referente à eventual natureza das águas superficiais, o que seria até mesmo contraditório com o conceito de todo unitário. Dessa forma, um curso d'água se torna internacional se qualquer de seus elementos superficiais atravessarem fronteiras, podendo o elemento transfronteiriço ser, inclusive, um canal artificial. ${ }^{55}$ Em todo o espectro de recursos hídricos transfronteiriços, apenas as águas subterrâneas não conectadas a um corpo d'água superficial restam excluídas do âmbito de aplicação das normas referentes aos cursos d'água internacionais, o que se deve ao caráter de subsidiariedade das águas subterrâneas presente na definição do escopo geográfico da UNWC. ${ }^{56}$

Entretanto, uma parcela da doutrina estabelece que, como as águas subterrâneas, os canais podem apenas compor um curso d'água internacional de forma subsidiária. ${ }^{57}$ Essa limitação do escopo geográfico se dá por meio do próximo elemento da definição a ser analisado, a partir de uma análise de razoabilidade contido na ideia da desembocadura comum, não havendo inicialmente qualquer limitação ao enquadramento do Silala enquanto um curso d'água internacional no que se refere ao primeiro elemento da definição abordada.

52 Idem.

53 Idem.

54 Arcari, Maurizio, “The Draft Articles on the Law...”. cit., p. 171.

55 Meshel, Tamar, "What's in a Name? The Silala Waters and the Applicability of International Watercourse Law”, Questions of International Law, Itália, vol. “Zoom-In” 39, 2017, p. 8.

56 Eckstein, Gabriel e Eckstein, Yoram, op. cit., p. 241.

57 Boisson de Chazournes, Laurence, Fresh Water in International Law, Oxford University Press, 2013, p. 28. 


\section{B. A Desembocadura Comum}

O segundo elemento da definição, a desembocadura comum, foi concebido enquanto um meio de limitar o escopo geográfico da UNWC, de forma a impedir que duas ou mais bacias de drenagem conectadas sazonalmente ou de forma artificial pudessem integrar um mesmo conjunto unitário para os propósitos da convenção. ${ }^{58}$ Esse elemento foi inserido na definição de cursos d'água internacionais em função da preocupação da CDI de que sistemas hídricos diversos com uma interação ínfima pudessem integrar o todo unitário de um mesmo curso d'água internacional. ${ }^{59}$

Criou-se, assim, um limite de razoabilidade, impedindo a fusão jurídica de dois cursos d'água distintos, que visava dar mais precisão à delimitação do escopo geográfico da UNWC.$^{60}$ Contudo, a existência de uma desembocadura comum não é um critério absoluto, pois ele incorpora em si exceções ligadas à sazonalidade e à outras complexidades dos sistemas hidrológicos. ${ }^{61}$ Assim, a efetiva análise da delimitação do escopo geográfico da UNWC deve ser realizada com fundamento no senso comum e julgamento prático da realidade do caso concreto. ${ }^{62}$

O último relator especial sobre o tema dos cursos d'água internacionais, Robert Rosenstock, sugeriu a retirada desse elemento do referido conceito sob a justificativa de se tratar de uma simplificação sem propósito e incorreta do ponto de vista hidrológico. ${ }^{63}$ Em contrapartida, outros

58 Rieu-Clarke, Alister et al., UN Watercourses Convention: User's Guide, Escócia, IHP-HELP Centre for Water Law, Policy and Science, 2012, p. 75.

59 International Law Commission, "Summary Record of the $2213^{\text {th }}$ Meeting", Yearbook of the International Law Commission, Estados Unidos da América, Organização das Nações Unidas, 1991, vol. I.

60 International Law Commission, "Report of the International Law Commission on the Work of its Forty-Third Session, 29 April-19 July 1991, Official Records of the General Assembly, Forty-Sixth Session, Supplement No. 10", Yearbook of the International Law Commission, Estados Unidos da América, Organização das Nações Unidas, 1991, vol. II, part two.

61 Rieu-Clarke, Alister et al., op. cit., p. 75.

62 International Law Commission, "Draft Articles on the Law of the Non-Navigational uses...”, cit., p. 91.

63 Rosenstock, Robert, "Second Report on the Law of Non-Navigational uses of International Watercourses", Yearbook of the International Law Commission, Estados Unidos da América, Organização das Nações Unidas, 1994, vol. II, núm. 1. 
membros da CDI consideraram essencial que o elemento da desembocadura comum compusesse a definição dos cursos d'água internacionais, visto que ele poderia auxiliar na identificação do elemento central de um sistema hídrico, de forma a facilitar a delimitação das fronteiras entre diferentes cursos d'água. ${ }^{64}$

O elemento da desembocadura comum tem uma função essencial no caso específico dos canais. Em sua ausência, seria possível utilizar os canais com o intuito de criar uma unidade artificial entre diferentes cursos d'água internacionais. ${ }^{65}$ Assim, os canais integram um curso d'água internacional por meio de uma análise de razoabilidade. Para alguns autores, isso significa que canais podem ser apenas elementos subsidiários de um curso d'água internacional, mas nunca o elemento central. ${ }^{66}$

Nesse sentido, seria imprudente especular acerca do enquadramento jurídico do Silala sem um embasamento fático sólido, uma vez que o elemento da desembocadura comum consiste em um índice de razoabilidade que pode apenas ser verificado por meio de uma minuciosa investigação dos atributos físicos do recurso hídrico compartilhado. No entanto, em suma, pode-se observar duas possibilidades principais que tem consequências jurídicas razoavelmente concretas, que são as versões antagônicas apresentadas pelas partes litigantes no caso Silala.

A primeira realiza-se na medida em que se considera que o Silala configura um curso natural transfronteiriço anterior à canalização, como proposto pelo Chile, de forma que os canais integrariam esse curso d'água internacional apenas enquanto elementos subsidiários, situação na qual haveria um forte argumento para que a CIJ enquadrasse o Silala no conceito de curso d'água internacional. Nesse contexto, como o fluxo de água canalizado serviria apenas para incrementar o fluxo natural do Silala, o critério de razoabilidade do elemento da desembocadura comum pesaria mais para o sentido da aplicação do direito dos cursos d'água internacionais a esse re-

64 International Law Commission, "Summary Record of the $2309^{\text {th }}$ Meeting", Yearbook of the International Law Commission, Estados Unidos da América, Organização das Nações Unidas, 1993, vol. I.

65 International Law Commission, "Report of the International Law Commission on the Work of its Forty-Fifth Session, 3 May-23 July 1993, Official Records of the General Assembly, Forty-Eighth Session, Supplement No. 10", Yearbook of the International Law Commission, Estados Unidos da América, Organização das Nações Unidas, 1993, vol. II, part two.

66 Boisson de Chazournes, Laurence, op. cit., p. 28. 
curso. ${ }^{67}$ Quanto à extensão do todo unitário do Silala ao aquífero transfronteiriço de onde são derivadas as águas canalizadas, ${ }^{68}$ o presente estado dos fatos não permite que sejam realizadas suposições a respeito desse recurso.

Em contraposição ao primeiro cenário, a segunda situação se realizaria no caso de o fluxo transfronteiriço do Silala ser inteiramente derivado das águas canalizadas, como sustentado pela Bolívia. Nesse contexto, o elemento central do sistema hídrico seria claramente o aquífero transfronteiriço do qual são derivados os canais. Assim, não seria razoável aplicar as normas referentes aos cursos d'água internacionais a um todo unitário cujo elemento central é claramente um aquífero. Dessa forma, poderia ser analisada a configuração do Silala enquanto integrante do todo unitário de um aquífero internacional nos termos do Projeto de Artigos sobre Aquíferos Transfronteiriços, ${ }^{69}$ mas tal enquadramento ultrapassa os limites de abrangência do presente estudo.

\section{A ORIGEM DO SILALA: CONTEXTUALIZAÇÃO HISTÓRICA E CIENTÍFICA}

A controvérsia relativa ao Silala apresenta uma complexidade factual singular, uma vez que as partes litigantes divergem não apenas em suas versões históricas, mas também científicas. No âmbito histórico, a disputa principal envolve a Bolívia ter ou não consentido à aplicação das normas jurídicas regime jurídico dos cursos d'água internacionais ao Silala. No âmbito das considerações científicas, por sua vez, discute-se o caráter natural ou artificial do fluxo do Silala.

67 Mulligan, Brendan e Eckstein, Gabriel, op.cit., p. 603.

68 Eckstein, Gabriel, "The Silala Basin: One of the Most Hydropolitically Vulnerable Basins in the World”, Estados Unidos da América, 2011, disponível em: https: / / www.internationalwa terlaw.org/blog/2011/10/27/the-silala-basin-one-of-the-most-hydropolitically-vulnerable-basinsin-the-world/.

69 Vucic, Mihajlo, "Silala Basin Dispute. Implications for the Interpretation of the Concept of International Watercourse”, Belgrade Law Review, Sérvia, núm. 4, 2017, p. 98; International Law Commission, "Draft Articles on the Law of Transboundary Aquifers", Yearbook of the International Law Commission, Estados Unidos da América, Organização das Nações Unidas, 2008, vol. II, part two, artigo 20 . 
Assim, a presente leitura contextual buscará apresentar de maneira detalhada estes fatores históricos e técnicos que serão essenciais à construção jurídica do caso. Dessa forma, as considerações históricas serão delineadas em torno dos acontecimentos que confirmam ou contestam a existência desse consentimento; enquanto os elementos técnicos serão delineados a partir das postulações do Chile e da Bolívia. Nesse sentido, o Chile alega que o Silala possui um fluxo transfronteiriço natural, ou seja, mesmo antes de qualquer eventual canalização, o Silala atravessava a fronteira chileno-boliviana em função da topografia da região onde ele se encontra. ${ }^{70}$ Por outro lado, a Bolívia busca trazer evidências de que o Silala atravessa a fronteira para o lado chileno em função de uma canalização recente. ${ }^{71}$

\section{Contexto Histórico}

O Caso sobre a Disputa acerca do Status e do Uso das Águas do Silala surgiu, principalmente, em decorrência da conflituosa relação entre o Chile e a Bolívia. Tal disputa se desenrolou tangencialmente à controvérsia sobre o acesso ao mar, que se resolveu judicialmente por meio da CIJ em favor do Chile em 2018. ${ }^{72}$ Contudo, antes de compreender as conexões entre a disputa relativa ao Silala e ao caso que se discutiu em 2018, é importante retornar ao momento inicial de ruptura. Desse modo, o conflito em relação ao Silala iniciou-se por um acontecimento aparentemente de pouca relevância que culminou em uma querela de proporções singulares no âmbito da gestão compartilhada de recursos hídricos transfronteiriços.

70 Republica de Chile, "Case of the Dispute over the Status and use of the Waters of the Silala (Chile vs. Bolívia). Application Instituting Proceedings”, Holanda, International Court of Justice, 2016, pp. 10-20, disponível em: https://www.icj-cij.org/files/case-related/162/16220160606-APP-01-00-EN.Pdf.

71 International Court of Justice, "Case of the Dispute over the Status and use of the Waters of the Silala (Chile vs. Bolivia). Order of 15 November 2018”, Holanda, International Court of Justice, 2018, p. 2, disponível em: https://www.icj-cij.org/files/case-related/162 /162-201 81115-ORD-01-O0-EN.pdf.

72 International Court of Justice, "Case of the Obligation to Negotiate Access to the Pacific Ocean (Bolivia vs. Chile)”, Holanda, International Court of Justice, 2018, pp. 54 e 55, disponível em: https: / /www.icj-cij.org/files/case-related/153/153-20181001-JUD-01OO-EN.pdf. 
No dia 4 de maio de 1996, o periódico El Diario publicou em primeira página a denúncia de que o Chile haveria desviado as águas do Silala de forma artificial. ${ }^{73}$ Em resposta a essa manchete, o chanceler boliviano Antonio Aranibar declarou que o Silala é um rio internacional, sendo a parte superior pertencente à Bolívia e a parte inferior ao Chile. Por meio dessa declaração, Aranibar também ressaltou que, apesar da canalização realizada no Silala, não existia qualquer desvio artificial que transportava suas águas em direção ao Chile. ${ }^{74}$

73 "El Diario alertó que Chile usó indebidamente aguas del Silala”, Bolívia, El Diario, 2016, disponível em: http://www.eldiario.net/noticias/2016/2016_04/nt160408/principal. php?n=63\&-el-diario-alerto-que-chile-uso-indebidamente-aguas-del-silala.

74 “COMUniCAdo DE PRENSA: El Ministro de Relaciones Exteriores y Culto, ante recientes publicaciones periodísticas referidas a una supuesta desviación de las aguas del fronterizo río Silala por parte de Chile y de una consiguiente presunta penetración chilena a territorio boliviano, tiene a bien informar a la opinión pública lo siguiente: 1. Por instrucciones del señor Canciller de la República Dr. Antonio Aranfoar Quiroga la presidencia de la Comisión Nacional de Soberanía y Limites presentó un informe técnico sobre la índole internacional del mencionado río. 2. El Silala es un río que tiene origen en una vertiente que brota al pie del cerro del mismo nombre, en territorio de Bolivia, e ingresa posteriormente a territorio de Chile. Dicho de otro modo, Bolivia es dueña del curso superior de ese río y Chile del inferior. 3. La existencia de canales de captación de aguas en esa zona se remonta a finales del siglo pasado, cuando empezaron los trabajos de conexión ferroviaria con Antofagasta, que continuaron tras la guerra de 1879. Esos datos se hallan registrados en los sucesivos informes sobre revisión de hitos en base a trabajos de campo efectuados a partir de 1906 y que cursan en los acuerdos que tienen que ver con la construcción de la citada línea férrea y con el uso del agua para las locomotoras de ese entonces. 4. La comisión mixta Bolivia-Chile levantó un mapa oficial que muestra con claridad que la llamada «represa»o «canalización Silala» se encuentra en territorio chileno. No existe, por tanto, ningún desvió de aguas. Todo esto quedó confirmado durante los trabajos de campo que realizó dicha Comisión Mixta en los años 1992, 1993 y 1994. 5. En la frontera boliviano-chilena no está asentado ningún batallón ni regimiento «Mejillones». De acuerdo con el departamento III del Comando General de Ejército, la guarnición militar boliviana que tiene puestos adelantados en San Pablo de Napa, Chiguana y Chela, y que patrullan la región del Silala, es el batallón 27 «Antofagasta» ubicado en la población de Kolcha-K y dependiente de la Décima división de Tupiza. En consecuencia, la versión sobre que el «Batallón Mejillones» compra agua a la empresa chilena «Cruz Blanca» carece de veracidad. Además, el batallón «Mejillones» está radicado en Huachacalla, departamento de Oruro. 6. En cuanto a que algunos hitos habrían sido removidos, la fotografía publicada en un periódico local presenta unos «mojones» incluso uno caído, que no corresponden a la demarcación efectuada por la Comisión Mixta, pues los hitos usados son metálicos todos sin excepción, desde la demarcación de 1906 y por norma del Protocolo Reglamentario de 1942. Consiguientemente, tampoco es cierto que hubiese producido una alteración de los hitos. 7. El informe 
Esta revista forma parte del acervo de la Biblioteca Jurídica Virtual del Instituto de Investigaciones Jurídicas de la UNAM

Além disso, o Dr. Teodoro Imaña-Castro, um dos acadêmicos bolivianos que compôs a comissão organizada pelo então prefeito de Potosí para verificar a situação real do Silala após as denúncias publicadas pelo El Diario, corroborou com a tese de Aranibar em seu relatório ao declarar que:

O curso do rio Silala [...] corre do Leste ao Sudeste em direção ao território chileno. Tem suas nascentes atrás da colina Silala em uma planície do leste da colina, em encostas, "olhos" ou nascentes de água (três principais e seis menores) [...] Essas águas provenientes dos nove "olhos" dão origem ao leito que, em virtude do terreno, se dirigem em direção ao Sudoeste, verso território chileno. ${ }^{75}$

Tais pronunciamentos indicam que, até o momento em que foram proferidos, a natureza do fluxo das águas do Silala por meio da fronteira ainda não era disputada. ${ }^{76}$ Entretanto, o governo boliviano não tardaria em contestar essas declarações. O próprio Aranibar chegou a se retratar publicamente por sua declaração, afirmando que o Silala não poderia sequer ser considerado um rio. ${ }^{77}$

No ano seguinte, o governo boliviano alterou radicalmente seu posicionamento e revogou a concessão que permitia ao Chile utilizar as águas provenientes do Silala, sob a justificativa de que o propósito da concessão teria

de la Comisión Nacional de Soberanía y Límites, en síntesis, deja constancia de que no hay ninguna obra o modificación, desvío de aguas ni alteración de hitos en la época actual. 8. No obstante, el Ministro de Relaciones Exteriores y Culto, dado que las aguas del río Silala son aprovechadas desde hace más de un siglo por Chile y no por Bolivia, y en razón de que el Estado boliviano debe ser beneficiario del costo de tales aguas, incorporará este tema en la agenda bilateral. 9. Finalmente la cancillería de la Republica recuerda que la vigilancia y resguardo material de las fronteras nacionales, son competencia de las Fuerzas Armadas y la Guardia Fronteriza de la Policía Boliviana. La Paz, mayo 7 de 1996. Dirección General De Información Diplomática”. Republica de Chile, op. cit., anexo 15.

75 "El curso del río Silala [...] corre Este a Sudoeste hacia territorio chileno. Tiene sus nacientes detrás del cerro Silala en una planicie del oriente del cerro, en vertientes, «ojos» o surgentes de agua (tres principales y seis menores) [...] Esas aguas provenientes de nueve «ojos» dan origen al cauce que, por la inclinación del terreno, de dirigen en dirección al Suroeste, hacia territorio chileno". Horzella, Barbara, "Negociaciones en torno al río Silala", Chile, Biblioteca del Congreso Nacional de Chile, 2016, disponível em: https: / /www.camara. $c l /$ verDoc.aspx?prmTIPO=DOCUMENTOCOMUNICACIONCUENTA\&prmlD $=13501$.

76 Republica de Chile, op. cit.

77 Quiroga, Antonio, “El mito del Silala”, Bolívia, 2002, p. 24, disponível em: http: / / anto niobaz.orgfree.com/descargas/Libro_Mito_Silala.pdf. 
sido subvertido. ${ }^{78}$ Tal concessão remonta às negociações de paz do último grande conflito entre o Chile e a Bolívia.

Tudo se iniciou no começo do século XX, logo após a guerra que culminou na perda do litoral para a Bolívia, além da divisão da Bacia do Silala, previamente localizada integralmente em território boliviano. ${ }^{79}$ Em 1904, o Tratado de Paz e Amizade celebrado entre o Chile e a Bolívia demonstrou pela primeira vez o reconhecimento bilateral da existência do Silala na qualidade de um rio, mesmo que mapas anteriores encomendados pelo Chile (1884) e pela Bolívia (1890) já o retratassem enquanto tal. ${ }^{80}$ Nesse sentido, surgem diferentes versões quanto ao início dos trabalhos de canalização. Autores bolivianos sugerem que a canalização se iniciou em 1888, logo antes da realização do mapa boliviano, enquanto a doutrina chilena se atém à versão de que os trabalhos teriam debutado em 1908, data posterior ao reconhecimento bilateral do Silala enquanto um rio internacional. ${ }^{81}$

Então, em 1906, o Chile concedeu à Ferrocarril de Antofagasta a Bolivia (FCBA) o direito de utilizar as águas do Silala em território chileno com o propósito de aumentar o fluxo de água que alimenta o porto de Antofagasta. ${ }^{82} \mathrm{~A}$ FCBA precisava de um fornecimento contínuo de água para possibilitar o funcionamento da malha ferroviária na região, e as águas do Silala se tornaram a solução ideal em função de sua qualidade e de sua localização. Assim, a empresa também requisitou à Bolívia uma canalização para incrementar o fluxo existente. Além disso, a FCBA ainda se dispôs a reservar um terço das águas para uso público, mas a Bolívia não demonstrou interesse nas águas até recentemente, quando declarou sua soberania absoluta sobre o recurso. ${ }^{83}$

Dessa forma, em 1908, o fluxo do Silala foi modificado pelo projeto de canalização possibilitado pela concessão da Bolívia. ${ }^{84}$ Tal concessão foi outorgada pela Prefeitura de Potosí à FCBA de forma completamente gra-

78 Rossi, Christopher, "The Transboundary Dispute Over the Waters of the Silala/Siloli", Stanford Journal of International Law, vol. 53, núm. 1, 2017, p. 55.

79 Mulligan, Brendan e Eckstein, Gabriel, op.cit., p. 598.

80 Republica de Chile, op. cit., p. 4.

81 Horzella, Barbara, op. cit., p. 7.

82 Republica de Chile, op. cit., p. 5.

83 Mulligan, Brendan e Eckstein, Gabriel, op. cit., p. 598.

84 Escobari, Andrés, "Los conflictos entre Bolivia y Chile”, Revista Macroregiones y Fronteras, Bolívia, núm. 11, 2016, p. 19. 
tuita e, apesar das dúvidas que circundam essa ausência de onerosidade, não há uma resposta clara acerca dos motivos que culminaram nesse compromisso. ${ }^{85}$ São encontradas na doutrina chilena interpretações dos termos da concessão boliviana para afirmar que, à época da construção dos canais, não havia dúvidas quanto ao status do Silala enquanto um rio transfronteiriço. ${ }^{86}$

A partir de 1962, a FCBA realizou uma conversão de sua frota de locomotivas, e o diesel começou a ser utilizado para substituir o motor à vapor. Assim, a água que era destinada ao abastecimento do sistema ferroviário começou a ser aproveitada para o consumo humano nas comunidades de Sierra Gorda e Baquedano, localizadas na parte chilena da fronteira. A partir de então, surgiram movimentos que urgiam ao governo boliviano para que cobrasse pela utilização das águas do Silala, o que eventualmente levaria à concepção de que o Chile teria uma dívida histórica em relação à Bolívia. ${ }^{87}$ Assim, com base nesses elementos fáticos, a Bolívia revogou a concessão para a utilização da águas do Silala em função da subversão de seu propósito inicial.

Em seguida à revogação da concessão, a Bolívia começou a tomar medidas unilaterais em relação ao Silala, adotando a postura de que o Silala estaria exclusivamente sobre seu domínio. ${ }^{88}$ Em 1999, a Bolívia autorizou a licitação das águas do Silala, o que foi contestado pelo Chile sob a justificativa de que não seria possível submeter as águas de um curso d'água internacional à uma licitação nacional. ${ }^{89}$ Não obstante aos protestos chilenos, a empresa boliviana, DUCTEC S.R.L., ganhou a licitação para a utilização das águas do Silala por 40 anos. Tal ato jurídico foi declarado pelo Chile como carente

85 Fundación Jaime Guzmán, "Silala: las aguas de la discordia”, Ideias \& Propuestas, Chile, núm. 39, 2009, p. 2, disponível em: https://www.jjguzman.cl/wp-content/uploads/2018/05/ iyp_39.pdf.

86 A concessão boliviana se refere ao Silala através dos termos águas, vertentes e rio. Apesar dos diferentes significados que possam ser atribuídos a essas palavras individualmente, a interpretação chilena postula que o verdadeiro significado desses termos pode ser encontrado na complementariedade mútua desses elementos, de forma que todos eles se referem às águas de vertente que formam um rio, que receberá a denominação comum de Silala. Von Chrismar, Julio, "El Silala es un río y como tal debe ser considerado", Política y Estrategia, Chile, núm. 93, 2004, pp. 86 e 87.

87 Horzella, Barbara, op. cit., p. 8.

88 Estado Plurinacional de Bolivia, "Canciller: Bolivia no amenaza y tiene derecho a ejercer soberanía sobre el Silala”, Bolívia, disponível em: http://www.comunicacion.gob.bo/? $q=20160324 / 20873$.

89 Horzella, Barbara, op. cit., p. 9. 
de eficácia, pois a própria licitação seria ilícita perante o direito internacional. Em resposta aos protestos chilenos, o chanceler boliviano declarou que a Bolívia não resistia a diálogo, mas ressalvou que o governo boliviano não estava aberto a reconsiderar o enquadramento do Silala enquanto um recurso hídrico doméstico. ${ }^{90}$

Assim, a DUCTEC tentou cobrar das companhias chilenas pela utilização das águas do Silala, mas sem sucesso. Em 2003, o fracasso da DUCTEC em realizar tal cobrança levou o governo boliviano a rescindir o contrato previamente realizado com a companhia boliviana. ${ }^{91}$ Eventualmente, os dois países começaram a cooperar, e o Silala foi apresentado como um dos tópicos da agenda bilateral em 2006.

As negociações levariam à uma proposta de acordo bilateral em 2009, que nunca chegou a ser adotado. ${ }^{92} \mathrm{Tal}$ acordo apresenta um modelo bem claro de repartição das águas do Silala. Em seu artigo 6o., o acordo estabelece:

As Partes estabelecem, em conformidade com o Artigo 2o., que do volume total das águas do Silala, ou Siloli, que fluem por meio da fronteira (100\%), 50\% correspondem, inicialmente, ao Estado Plurinacional de Bolivia, são de sua livre disponibilidade e as poderá utilizar em seu território ou autorizar sua captação para seu uso por terceiros, incluindo sua condução ao Chile. Essa porcentagem poderá ser incrementada em favor da Bolivia, em função dos resultados dos estudos conjuntos que forem implementados no âmbito do presente Acordo. ${ }^{93}$

Assim, a água poderia ser utilizada pela Bolívia ou continuar sendo conduzida ao Chile, que em contrapartida pagaria pela porcentagem utilizada conforme os valores estabelecidos pelo Ministério do Meio Ambiente

90 Idem.

91 Mulligan, Brendan e Eckstein, Gabriel, op. cit., p. 598.

92 Republica de Chile, op. cit., p. 7.

93 “Las Partes establecen, de conformidad con el Artículo 2, que del volumen total del agua del Silala o Siloli, que fluye a través de la frontera (100\%), el 50\% corresponde, inicialmente, al Estado Plurinacional de Bolivia, es de su libre disponibilidad y lo podrá utilizar en su territorio o autorizar su captación para su uso por terceros, incluyendo su conducción a Chile. Este porcentaje podrá ser incrementado a favor de Bolivia, en función de los resultados de los estudios conjuntos que se lleven a cabo en el marco del presente Acuerdo". Estado Plurinacional de Bolivia e Republica de Chile, "El acuerdo inicial sobre el Silala, o Siloli", Estados Unidos da América, artigo 6o., disponível em: https: / / www.internationalwaterlaw.org/ documents/regionaldocs/Silala/SilalaAgreement2009_Spanish.pdf. 
e Água da Bolívia. ${ }^{94}$ Entretanto, em 2010, a Bolívia retornou ao seu posicionamento anterior de clamar soberania absoluta sobre as águas do Silala, afirmando que não se tratava de um curso d'água internacional. O governo boliviano chegou até mesmo a indicar que o Chile deveria pagar mais de um bilhão de dólares a título de dívida histórica pela utilização das águas do Silala. Assim, a Bolívia tentou inserir um artigo no acordo sobre a dívida histórica, o que culminou fatalmente na cessação das negociações. ${ }^{95}$

Concomitantemente às negociações, a Bolívia começou a analisar uma série de projetos a serem implementados no Silala. O governo boliviano cogitou, inclusive, engarrafar a água do Silala para fins comerciais com o slogan Drink Silala water for sovereignty, além de realizar um estudo sobre a viabilidade de implementar uma usina hidrelétrica no lado boliviano da fronteira. ${ }^{96}$ Além disso, foi inaugurado uma incubadora de trutas e está sendo estudada a viabilidade de um bombeamento de águas até a Laguna Colorada, projetos esses que consumiriam a integridade das águas do Silala. ${ }^{97}$

E assim, em 6 de junho de 2016, o Chile iniciou os procedimentos perante a CIJ. ${ }^{98} \mathrm{O}$ processo ainda está em seu estágio inicial, sendo ainda muito precipitado deduzir conclusões definitivas sobre os fatos conflitantes que acabam de ser descritos. Como pode ser observado no desenvolvimento histórico apresentado, existe uma complexa dinâmica de cooperação entre as partes desse conflito, de forma que grande parte dos fatos são disputados pelas partes. Portanto, o caráter instável das negociações entre o Chile e a Bolívia dificultam imensamente a análise de um eventual consentimento boliviano ao enquadramento do Silala enquanto um curso d'água internacional.

\section{Contexto Cientifico}

Como discutido anteriormente, o fluxo hídrico do Silala é influenciado por alguns canais artificiais, e as partes disputam, essencialmente, o nível de

94 Ibidem, artigo 13.

95 Mulligan, Brendan e Eckstein, Gabriel, op. cit., p. 600.

96 Galland, Franck, "L'eau: un problème stratégique pour le nord du Chili”, GÉOÉCONOMIE, França, núm. 49, 2009, p. 98.

97 Horzella, Barbara, op. cit., pp. 12 e 13.

98 Republica de Chile, op. cit. 
influência que essas estruturas artificiais exercem sobre o fluxo do sistema. O Chile sustenta que os canais não afetam o curso transfronteiriço do Silala. Assim, para fins didáticos, é realizada uma distinção entre um canal e um rio canalizado:

O canal seria uma construção artificial realizada pelo homem para conduzir a passagem da água por um lugar por meio do qual não passaria de forma natural. Um rio canalizado pressupõe a existência prévia de um curso d'água que flui de forma natural, e sua canalização se realiza para evitar transbordamentos em épocas de cheia, ou para reduzir a evaporação. Em termos jurídicos, um rio canalizado não perde sua condição de rio, e tal é o caso do rio Silala. ${ }^{99}$

Em linhas gerais, o Silala é classificado enquanto um rio canalizado pelo Chile, e como um canal pela Bolívia. ${ }^{100}$ Nesse sentido, o Chile baseia-se em evidências geográficas, topográficas e históricas para afirmar que as nascentes do Silala fluíam da Bolívia para o Chile mesmo antes da canalização. Essa tese encontra subsídio em estudos realizados em 2009 por uma empresa boliviana responsável pela análise do potencial hidroelétrico do Silala.

Esses estudos incluem estudo topográfico que teria demonstrado que os canais foram construídos para tornar mais eficiente o fluxo de água, não havendo desvio no sentido do rio. ${ }^{101}$ Em consonância com esses indícios, um estudo realizado em 2017 por uma comissão de especialistas do Chile, em colaboração com o Servicio Nacional de Geología y Minería (SERNAGEOMIN), constatou que a formação atual do Silala foi consolidada há 11.500 anos, e que o surgimento do vale de drenagem que possibilita o fluxo transfronteiriço data de aproximadamente 4 milhões de anos atrás. ${ }^{102}$

99 "El canal sería una construcción artificial hecha por el hombre para conducir el paso del agua por un lugar a través del cual nunca ha fluido en forma natural. Un río canalizado supone la existencia previa de un curso de agua que fluye en forma natural, y su canalización se realiza para evitar desbordes en época de crecidas, o para reducir la evaporación. En términos de derecho, un río canalizado no pierde su condición de río; tal es el caso del Silala”. Horzella, Barbara, op. cit., pp. 3 e 4.

100 Corporación Minera de Bolivia, "Sergeomin: el Silala no es un río, es un manantial”, Bolívia, 2018, disponível em: http://www.comibol.gob.bo/index.php/24-noticias-inicio/ 1736-sergeomin-el-silala-no-es-un-rio-es-un-manantial; Republica de Chile, op. cit.

101 Mulligan, Brendan e Eckstein, Gabriel, op. cit., pp. 595-597.

102 Sernageomin, “Curso fluvial del río Silala tendría 11.500 años”, Chile, 2017, disponível em: http: / / www.sernageomin.cl/curso-fluvial-del-rio-silala-tendria-11-500-anos/. 
Em contrapartida, a Bolívia baseia-se em um estudo realizado pelo Servicio Geológico y Técnica de Minas de Bolívia (SERGEOTECMIN) para afirmar que grande parte dessas nascentes fluem por meio de pequenos canais artificiais que se unificam em um canal principal no território boliviano. ${ }^{103} \mathrm{O}$ estudo sugeriu, em síntese, que o Silala seria exclusivamente fruto de obras artificiais, não possuindo, assim, as características essenciais de um sistema hidrológico natural. ${ }^{104}$ Conforme um acadêmico boliviano:

Pelos diversos estudos e investigações realizados por especialistas no campo, pode-se concluir que as águas do Silala são mananciais e que, em consequência, não configuram, em sentido estrito, um rio. Embora essas águas fluam de um lugar a outro, não o fazem de forma natural, pois foi necessário construir diversas estruturas para sua captação e transporte [...] Dessa informação conclui-se que os olhos de água ou mananciais de onde provém estas águas estão localizados integralmente em território boliviano. ${ }^{105}$

Segundo um dos maiores defensores da teoria do "mito do Silala", Antonio Bazoberry, o Silala não passaria de uma invenção do engenheiro que estava a serviço do Chile na época da concessão da permissão para a canalização. A argumentação apresentada funda-se na suposta manipulação de mapas à época da canalização e no estudo realizado em 2003 pelo SERGEOTECMIN sobre o Silala.

Como se pode observar, ainda não foi realizado um estudo exaustivo e imparcial que determinasse a natureza das águas do Silala, de forma que essa matéria fática permanece em aberto. ${ }^{106}$ Assim, ainda restam diversos elementos probatórios a serem produzidos no caso, podendo este ser significativamente influenciado em decorrência da prevalência de determinados aspectos factuais.

103 Mulligan, Brendan e Eckstein, Gabriel, op. cit., pp. 595-597.

104 Quiroga, Antonio, op. cit., pp. 24-30.

105 "Por los diversos estudios e investigaciones realizados por especialistas en el campo, se puede concluir que las aguas del Silala son manantiales y que, por consiguiente, no configuran, en sentido estricto, un río. Si bien estas aguas discurren de un lugar a otro, no lo hacen de manera natural, pues ha sido necesario construir diversas obras para su recolección y transporte [...] De esta información se desprende que los ojos de agua o manantiales de donde proviene esta agua están ubicados, en su integridad, en territorio boliviano”. Horzella, Barbara, op. cit., p. 3.

106 Escobari, Andrés, op. cit., pp. 17 e 18. 
É importante ressaltar que a discussão conceitual dos termos científicos não deve ser confundida com o elemento central da disputa, que é o enquadramento jurídico do Silala. O fluxo artificial ou natural desse sistema hídrico interfere diretamente nas variáveis jurídicas que foram analisados no capítulo anterior, mas esse não é o único elemento que deve ser considerado na classificação jurídica de um recurso hídrico transfronteiriço, devendo também ser abordada a questão da existência de uma desembocadura comum, como previamente demonstrado.

Em síntese, os Estados litigantes do caso Silala disputam fortemente a natureza dos fatos históricos e científicos que circundam a controvérsia. Essas visões antagônicas são defendidas e reproduzidas de forma evidentemente parcial pela doutrina e imprensa dos dois países, o que dificulta a tarefa de reconstituir os fatos por meio de uma lógica coerente e consistente. Entretanto, esse antagonismo radical possibilita também a análise das consequências jurídicas imediatas das versões apresentadas pelas partes frente ao direito internacional, o que seria inviável em um cenário de posicionamentos mais convergentes. Assim, resta claro que, apesar das incertezas quanto aos aspectos científicos que permeiam a controvérsia acerca do Silala, a construção adotada pela CIJ quanto ao escopo do regime jurídico dos cursos d'água internacionais poderá elucidar o enquadramento de diversos outros recursos hídricos transfronteiriços que se encontram nos limites desse conceito. Assim, esse movimento será de suma importância para a gestão de recursos hídricos compartilhados em todo o mundo.

\section{CONCLUSÃO}

O caso Silala levanta os questionamentos mais controversos no âmbito do direito aplicável a cursos d'água internacionais, e o julgamento dessa querela terá efeitos significativos na gestão integrada de recursos hídricos por todo o mundo. Resta claro que a CIJ possui uma ampla margem de argumentação jurídica para deferir ou indeferir a aplicação do direito dos cursos d'água internacionais ao Silala. Além disso, os novos elementos probatórios que serão trazidos ao caso certamente terão uma forte influência so- 
bre o resultado da controvérsia, visto que há discordância das partes sobre diversos pontos fundamentais do contexto fático. A definição dos cursos d'água internacionais ainda possui muito espaço para ser desenvolvida, visto que cada sistema hídrico tem características peculiares que integram e complementam o seu todo unitário, de forma que sempre surgirão novos questionamentos sobre a abrangência do escopo geográfico desse termo, uma análise que perpassa uma cada vez mais complexa consideração de razoabilidade.

Além disso, as próprias consequências do enquadramento jurídico de determinados sistemas hídricos na definição de curso d'água internacional ainda permanecem incertas, sendo que nenhum caso similar havia antes sido julgado exclusivamente sob a égide do regime jurídico costumeiro dos cursos d'água internacionais. Dessa forma, mesmo que a CIJ tenha tido a oportunidade de tecer contribuições essenciais à compreensão e aplicação dos princípios do uso equitativo de recursos compartilhados e da cooperação em casos fundados em supostas violações de normas convencionais, o caso Silala pode eventualmente ser o primeiro precedente a discutir as extensões e consequências dessas normas costumeiras de forma mais sistemática.

Assim, com os possíveis cenários que se apresentam em face dos pressupostos adotados, é possível observar que a CIJ terá que se debruçar sobre questões jurídicas complexas que se conectam à decisão central em relação ao enquadramento jurídico do Silala. Independentemente da efetiva classificação do Silala enquanto um curso d'água internacional, a essência das potenciais contribuições que a CIJ pode trazer ao direito internacional estão nas justificativas que serão utilizadas para tal. Portanto, atrelado ao futuro do Silala está o futuro do direito dos cursos d'água internacionais, que poderá ser amplamente influenciado não apenas pelo resultado, mas também pelo raciocínio jurídico que o sustentará.

Dessa forma, mesmo que seja ainda muito cedo no presente estado do processo do caso Silala para formular considerações conclusivas sobre os elementos jurídicos disputados pelas partes litigantes, é evidente que matérias de grande relevância para o direito internacional podem ser influenciadas através do julgamento dessa controvérsia. Independentemente do posicionamento que a CIJ decidir adotar, é possível constatar que o caso Silala trará grandes contribuições para o direito internacional. 


\section{AgRADECIMENTOS}

O presente trabalho é resultado de pesquisa orientada pelo Prof. Lucas Carlos Lima, a quem agradeço imensamente pelas valiosas contribuições, que tornaram essa produção possível. Agradeço também ao Prof. Maurizio Arcari e ao Prof. Aziz Saliba pelos proveitosos comentários. Ressalta-se, entretanto, que todas as eventuais falhas são de exclusiva responsabilidade do autor.

\section{BIBLIOGRAFIA}

ARCARI, Maurizio, "The Codification of the Law of International Watercourses: The Draft Articles Adopted by the International Law Commission”, Anuario Español de Derecho Internacional, Espanha, vol. 13, 1997.

ARCARI, Maurizio, “The Draft Articles on the Law of International Watercourses Adopted by the International Law Commission: An Overview and some Remarks on Selected Issues", Natural Resources Forum, vol. 21, núm. 3, 1997.

ARCARI, Maurizio e TANZI, Attila, The United Nations Convention on the Law of International Watercourses: A Framework for Sharing, Holanda, Kluwer Law International, 2001.

Boisson de Chazournes, Laurence, Fresh Water in International Law, Oxford University Press, 2013.

Caflisch, Lucius, "Règles Générales du Droit des Cours d'Eau Internationaux", Collected Courses of the Hague Academy of International Law, Brill-Nijhoff, vol. 219, 1989.

Cavalcanti, Themistocles, "Problemas Jurídicos dos Rios Internacionais", Revista de Ciência Política, Brasil, vol. 23. núm. 3, 1980.

Corporación Minera de Bolivia, "Sergeomin: el Silala no es un río, es un manantial”, Bolívia, 2018, disponível em: http: / / www.comibol.gob.bo/index. php/24-noticias-inicio/1736-sergeomin-el-silala-no-es-un-rio-es-un-manantial.

ECKSTEIN, Gabriel, "The Silala Basin: One of the Most Hydropolitically Vulnerable Basins in the World”, Estados Unidos da América, 2011, dis- 
Esta revista forma parte del acervo de la Biblioteca Jurídica Virtual del Instituto de Investigaciones Jurídicas de la UNAM

ponível em: https: / / www.internationalwaterlaw.org/blog/2011/10/27/the -silala-basin-one-of-the-most-hydropolitically-vulnerable-basins-in-the-world/. ECKSTEIn, Gabriel e ECKSTEIn, Yoram, "A Hydrogeological Approach to Transboundary Ground Water Resources and International Law", Am. U. Int'1 L. Rev, vol. 19, 2003.

"El Diario alertó que Chile usó indebidamente aguas del Silala”, Bolívia, El Diario, 2016, disponível em: http: / /www.eldiario.net/noticias/2016/2016_04 /nt $160408 /$ principal.php? $n=63 \&$-el-diario-alerto-que-chile-uso-indebidamen te-aguas-del-silala.

ESCOBARI, Andrés, "Los conflictos entre Bolivia y Chile", Revista Macroregiones y Fronteras, Bolívia, núm. 11, 2016.

Estado Plurinacional de Bolivia, "Canciller: Bolivia no amenaza y tiene derecho a ejercer soberanía sobre el Silala”, Bolívia, disponível em: http: / / www.comunicacion.gob.bo/?q=20160324/20873.

Estado Plurinacional de Bolivia e Republica De Chile, "El acuerdo inicial sobre el Silala, o Siloli”, Estados Unidos da América, artigo 6o., disponível em: https://www.internationalwaterlaw.org/documents/regional docs/Silala/SilalaAgreement2009_Spanish.pdf.

FuENTES, Ximena, "Solicitud de inicio de procedimiento de la República de Chile contra el Estado Plurinacional de Bolivia ante la Corte Internacional de Justicia por el aprovechamiento de las aguas del río Silala (6 de junio del 2016)", Revista Tribuna Internacional, Chile, vol. 5, núm. 9, 2016.

Fundación Jaime Guzmán, "Silala: las aguas de la discordia", Ideias \& Propuestas, Chile, núm. 39, 2009, p. 2, disponível em: https: / /www.fjguzman. cl/wp-content/uploads/2018/05/iyp_39.pdf.

GALLAND, Franck, “L'eau: un problème stratégique pour le nord du Chili”, GÉOÉCONOMIE, França, núm. 49, 2009.

Horzella, Barbara, "Negociaciones en torno al río Silala”, Chile, Biblioteca del Congreso Nacional de Chile, 2016, disponível em: https: / / Www. camara.cl/verDoc.aspx?prmTIPO=DOCUMENTOCOMUNICACIONCUENTA\&prmlD $=13501$.

INSTITUT DE DROIT INTERNATIONAL, "Réglementation internationale de l'usage des cours d'eau internationaux en dehors de l'exercice du droit de navigation. Session de Madrid (1911)", Suíça, Institut de Droit International, 1911, disponível em: http://www.idi-iil.org/app/ uploads/2017/06/1911_mad_01_fr.pdf. 
INSTITUT DE DROIT INTERNATIONAL, "Utilisation des eaux internationales non maritimes (en dehors de la navigation). Session de Salzbourg (1961)", Suíça, Institut de Droit International, 1961, disponível em: http: / / www.idi-iil.org/app/uploads/2017/06/1961_salz_01_fr.pdf.

InTERnational COURT OF Justice, "Case Concerning the Gabcikovo-Nagymaros Project (Hungary/Slovakia)", Holanda, International Court of Justice, 1997, disponível em: https://www.icj-cij.org/files/case-related /92 /092-19970925-JUD-01-00-EN.pdf.

INTERNATIONAL COURT OF JUSTICE, "Case of the Dispute over the Status and use of the Waters of the Silala (Chile vs. Bolivia). Order of 15 November 2018", Holanda, International Court of Justice, 2018, disponível em: https: / / www.icj-cij.org/files / case-related / 162 / 162-20181115-ORD01-00-EN.pdf.

International Court of Justice, "Case of the Obligation to Negotiate Access to the Pacific Ocean (Bolivia vs. Chile)", Holanda, International Court of Justice, 2018, disponível em: https://www.icj-cij.org/files/case -related /153/153-20181001-JUD-01-00-EN.pdf.

INTERNATIONAL LAW AsSOCIATION, “The Helsinki Rules”, Estados Unidos da América, International Law Association, 1966, artigo II, disponível em: https: / / www.internationalwaterlaw.org/documents/intldocs/ILA / Helsinki _Rules-original_with_comments.pdf.

InTERnational LaW COMmission, "Draft Articles on the Law of the Non-Navigational uses of International Watercourses and Commentaries Thereto and Resolution on Transboundary Confined Groundwater", Yearbook of the International Law Commission, Estados Unidos da América, Organização das Nações Unidas, 1994, vol. II, part two.

InTERnATIONAL LAW COMMISSION, "Draft Articles on the Law of Transboundary Aquifers", Yearbook of the International Law Commission, Estados Unidos da América, Organização das Nações Unidas, 2008, vol. II, part two, artigo 2o.

INTERNATIONAL LAW COMMISSION, "Report of the International Law Commission on the Work of its Forty-Third Session, 29 April-19 July 1991, Official Records of the General Assembly, Forty-Sixth Session, Supplement No. 10", Yearbook of the International Law Commission, Estados Unidos da América, Organização das Nações Unidas, 1991, vol. II, part two.

INTERNATIONAL LAW COMMISSION, "Report of the International Law Commission on the Work of its Forty-Fifth Session, 3 May-23 July 1993, Offi- 
cial Records of the General Assembly, Forty-Eighth Session, Supplement No. 10", Yearbook of the International Law Commission, Estados Unidos da América, Organização das Nações Unidas, 1993, vol. II, part two.

INTERNATIONAL LAW COMMISSION, "Summary Record of the $1554^{\text {th }}$ Meeting”, Yearbook of the International Law Commission, Estados Unidos da América, Organização das Nações Unidas, 1979, vol. 1.

INTERNATIONAL LAW COMMISSION, "Summary Record of the $2213^{\text {th }}$ Meeting”, Yearbook of the International Law Commission, Estados Unidos da América, Organização das Nações Unidas, 1991.

InTERnATIONAL LAW COMmission, "Summary Record of the $2309^{\text {th }}$ Meeting", Yearbook of the International Law Commission, Estados Unidos da América, Organização das Nações Unidas, 1993, vol. I.

KEARNEY, Richard, "First Report on the Law of Non-Navigational uses of International Watercourses", Yearbook of the International Law Commission, Estados Unidos da América, Organização das Nações Unidas, 1976, vol. II, núm. 1.

LiMA, Lucas, "The Silala Waters Dispute before the ICJ and the Law on the use of International Rivers for Non-Navigational Purposes", Questions of International Law, Itália, vol. “Zoom-In” 39, 2017.

MCCAFFreY, Stephen, "Seventh Report on the Law of Non-Navigational uses of International Watercourses", Yearbook of the International Law Commission, Estados Unidos da América, Organização das Nações Unidas, 1991, vol. II, núm. 1.

MCCAFfreY, Stephen, "The UN Convention on the Law of the Non-Navigational uses of International Watercourses: Prospects and Pitfalls", Suíça, p. 18, disponível em: https: / /www.unece.org/fileadmin/DAM/env/ water/cwc/legal/UNConvention_McCaffrey.pdf.

Meshel, Tamar, "What's in a Name? The Silala Waters and the Applicability of International Watercourse Law", Questions of International Law, Itália, vol. “Zoom-In” 39, 2017.

Mulligan, Brendan e ECKSTEIN, Gabriel, "The Silala/Siloli Watershed: Dispute over the Most Vulnerable Basin in South America", Water Resources Development, Estados Unidos da América, vol. 27, núm. 3, 2011.

Quiroga, Antonio, "El mito del Silala”, Bolívia, 2002, p. 24, disponível em: http: / / antoniobaz.orgfree.com/descargas/Libro_Mito_Silala.pdf. 
REPUBLIC OF FINLAND, "Replies of Governments to the Commission's Questionnaire", Yearbook of the International Law Commission, Estados Unidos da América, Organização das Nações Unidas, 1976, vol. II, núm. 1.

Republica Argentina, "Replies of Governments to the Commission's Questionnaire", Yearbook of the International Law Commission, Estados Unidos da América, Organização das Nações Unidas, 1976, vol. II, núm. 1.

RePublica DE CHILE, "Case of the Dispute over the Status and use of the Waters of the Silala (Chile vs. Bolívia). Application Instituting Proceedings", Holanda, International Court of Justice, 2016, pp. 10-20, disponível em: https: / / www.icj-cij.org/files/case-related/162 / 162-20160606-APP-O 1-O0-EN.pdf.

RePública FEDERATIVA DO BRASIL, "Declaration of Asunción on the Use of International Rivers", Itália, disponível em: http: / / www.fao.org/docrep /005/W9549e/W9549e03.htm.

REPÚBLICA FEDERATIVA DO BRASIL, "Replies of Governments to the Commission's Questionnaire", Yearbook of the International Law Commission, Estados Unidos da América, Organização das Nações Unidas, 1976, vol. II, núm. 1 .

Rieu-Clarke, Alister et al., UNWatercourses Convention: User's Guide, Escócia, IHP-HELP Centre for Water Law, Policy and Science, 2012.

Rosenstock, Robert, "Second Report on the Law of Non-Navigational uses of International Watercourses", Yearbook of the International Law Commission, Estados Unidos da América, Organização das Nações Unidas, 1994, vol. II, núm. 1.

Rossi, Christopher, "The Transboundary Dispute Over the Waters of the Silala/Siloli”, Stanford Journal of International Law, vol. 53, núm. 1, 2017. SCHWEBEL, Stephen, "First Report on the Law of Non-Navigational uses of International Watercourses", Yearbook of the International Law Commission, Estados Unidos da América, Organização das Nações Unidas, 1979, vol. II, núm. 1.

SCHWEBEL, Stephen, "Second Report on the Law of Non-Navigational uses of International Watercourses", Yearbook of the International Law Commission, Estados Unidos da América, Organização das Nações Unidas, 1982, vol. II, núm. 1.

Sernageomin, "Curso fluvial del río Silala tendría 11.500 años", Chile, 2017, disponível em: http: / / www.sernageomin.cl/curso-fluvial-del-rio-sila la-tendria-11-500-anos/. 
SETTE-CÂMARA, José, "Pollution of International Rivers", Collected Courses of the Hague Academy of International Law, Holanda, Leiden, Brill-Nijhoff, vol. $186,1984$.

TECLAFF, Ludwik, "Evolution of the River Basin Concept in National and International Water Law", Natural Resources Journal, Estados Unidos da América, vol. 36, núm. 2, 1996.

United Nations, "UN Watercourses Convention”, Estados Unidos da América, disponível em: http: / / www.unwatercoursesconvention.org/the-con vention/.

United Nations EnVIROnMENTAl Programme, Hydropolitical Vulnerability and Resilience along International Waters, Quênia, UNEP, 2007.

United Nations Treaty Collection, "Status of the Convention on the Law of the Non-Navigational Uses of International Watercourses", Estados Unidos da América, disponível em: https: / / treaties.un.org/pages/ ViewDetails.aspx? src $=I N D \& m t d s g \_n o=X X V I I-12 \&$ chapter $=27 \& l a n g=e n$.

UNITED STATES OF AMÉRICA, "Replies of Governments to the Commission's Questionnaire", Yearbook of the International Law Commission, Estados Unidos da América, Organização das Nações Unidas, 1976, vol. II, núm. 1.

VON CHRISMAR, Julio, "El Silala es un río y como tal debe ser considerado", Política y Estrategia, Chile, núm. 93, 2004.

VucIC, Mihajlo, "Silala Basin Dispute. Implications for the Interpretation of the Concept of International Watercourse", Belgrade Law Review, Sérvia, núm. 4, 2017.

Wescoat, James, "Beyond the River Basin: Changing Geography of International Water Law Problems and International Watercourses Law”, Colorado Journal of International Environmental Law and Policy, Estados Unidos da América, vol. 3, núm. 1, 1992. 